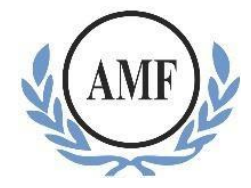

\title{
Síndrome de Burnout e Engajamento no Trabalho: um Estudo a Partir de Trabalhadores do Comércio
}

\author{
Luisa Gründling da Cunha ${ }^{1}$ \\ Adriane Fabricio ${ }^{2}$ \\ Felipe Cavalheiro zaluski ${ }^{3}$
}

\begin{abstract}
Resumo: Este estudo objetivou identificar possíveis relações entre as dimensões da Síndrome de Burnout (exaustão emocional, despersonalização e a baixa realização profissional) e o Engajamento no Trabalho (vigor, dedicação e absorção) em funcionários do comércio da cidade de Ijuí, localizada no Estado do Rio Grande do Sul. Para tanto, utilizou, na mensuração da síndrome de burnout, o instrumento MBI-GS dos autores Maslach e Jackson (1986) e, para engajamento no trabalho, o UWES, dos autores Schaufeli e Bakker (2003), com uma abordagem qualitativa e quantitativa, objetivo descritivo e explicativo. Foram utilizados, como procedimentos técnicos, o bibliográfico, o levantamento e a pesquisa de campo. Conclui-se que nas dimensões da síndrome de Burnout, foi possível observar, primeiramente, que a amostra pesquisada não apresenta presença significativa da Síndrome, segundo critérios estabelecidos por Schaufeli et al. (2002), uma vez que médias baixas de exaustão e despersonalização, e altas de realização ou envolvimento no trabalho, não representam indicativos significativos de Burnout. Em conclusão à identificação e à análise das dimensões do Engajamento no Trabalho, a amostra apresentou indicativo de estar engajada - segundo Schaufeli e Bakker (2003), quanto mais alto o escore identificado em vigor, dedicação e absorção, maior será o Engajamento no Trabalho.
\end{abstract}

Palavras-chave: Síndrome de Burnout; engajamento no trabalho; Setor de Comércio.

\section{Burnout Syndrome and Work Engagement: a Study from Trade Workers}

Abstract: This study aimed to identify possible relationships between the dimensions of Burnout Syndrome (emotional exhaustion, depersonalization and low professional

\footnotetext{
${ }^{1}$ Bacharel em Administração de Empresas pela Universidade Regional do Noroeste do Estado do Rio Grande do Sul (UNIJUI); instrutora de idiomas e Assistente de PCP, fluente em Inglês e com experiência no exterior; tem experiência nas áreas de vendas, marketing, publicidade e propaganda, gestão de pessoas e planejamento e controle de produção. Email: luisagcunha91@ gmail.com.

${ }^{2}$ Doutoranda em Administração pela Universidade Federal de Santa Maria (UFSM); Mestra em Engenharia de Produção (UFSM); Especializanda em Formação Pedagógica de Professores para Educação Profissional pelo Instituto Federal Farroupilha (IF-Farroupilha); Especialista em Gestão de Pessoas e Desenvolvimento de Talentos pela Sociedade Educacional Três de Maio (SETREM); Bacharela em Administração (SETREM); Experiência com graduação, pós-graduação, treinamentos, palestras e consultoria com os seguintes temas: Desafios do mercado de trabalho; Gestão de Pessoas; Gestão Estratégia de Pessoas; Comportamento Organizacional; Doenças comportamentais; Estresse e Trabalho; Riscos Psicossociais e sua relação com o ambiente de trabalho ; Qualidade de Vida no Trabalho; Florescimento no Trabalho; Engajamento; Comprometimento; Satisfação; Bem-estar; Mudança Organizacional; Métricas e Indicadores de GP e CO; Papel do Gestor na GP e CO; Comportamento Organizacional Positivo; Psicologia Positiva Aplicada a Gestão de Pessoas; Cenários e Tendências em Gestão de Pessoas; Metodologia da pesquisa. E-mail: adrianefabricio@yahoo.com.br.

3 Doutorando em Administração pela Universidade Federal de Santa Maria (UFSM); Mestre em Desenvolvimento pela Universidade Regional do Noroeste do Estado do Rio Grande do Sul (UNIJUI); Especialista em Gestão Empresarial pela Faculdade Futura (ICETEC); Especialista em Docência do Ensino Superior em Adminstração (ICETEC); Bacharel em Administração (UNIJUI); Integrante do Grupo de Pesquisa Gestão Estratégica no Contexto da Competitividade e do Desenvolvimento Local e Regional - GPCOM (PPGDR/UNIJUÍ) e do Grupo de Pesquisa Espaço Construído, Sustentabilidade e Tecnologias - GTEC (DCEENG/UNIJUÍ). E-mail: felipezaluski@ hotmail.com.
} 
achievement) and Engagement at Work (vigor, dedication and absorption) in commercial employees of the city of Ijuí, located in Rio Grande do Sul State. To do so, it used the MBI-GS instrument by Maslach and Jackson (1986) to measure burnout syndrome and, for work engagement, the UWES by Schaufeli and Bakker (2003). qualitative and quantitative, descriptive and explanatory objective. The technical procedures used were bibliographic, survey and field research. It was concluded that in the dimensions of Burnout syndrome, it was possible to observe, first, that the researched sample does not present significant presence of the syndrome, according to criteria established by Schaufeli et al. (2002), since low exhaustion and depersonalization averages, and high accomplishment or involvement at work, do not represent significant indications of Burnout. In conclusion the identification and analysis of the dimensions of Engagement at Work, the sample showed indicative of being engaged - according to Schaufeli and Bakker (2003) the higher the identified score in force, dedication and absorption, the greater will be the Engagement at Work.

Keywords: Burnout Syndrome; engagement at work; Commerce Sector.

Sindrome de Burnout y Compromiso de Trabajo: un Estudio de Trabajadores Comerciales

Resumen: Este estudio tuvo como objetivo identificar posibles relaciones entre las dimensiones del Síndrome de Burnout (agotamiento emocional, despersonalización y bajo rendimiento profesional) y el compromiso en el trabajo (vigor, dedicación y absorción) en empleados comerciales de la ciudad de Ijuí, ubicada en el estado de Río Grande do Sul. Para ello, utilizó el instrumento MBI-GS de Maslach y Jackson (1986) para medir el síndrome de burnout y, para el trabajo, el UWES de Schaufeli y Bakker (2003), objetivo cualitativo y cuantitativo, descriptivo y explicativo. Los procedimientos técnicos utilizados fueron bibliográficos, de encuestas e investigaciones de campo. Se concluyó que, en las dimensiones del síndrome de Burnout, fue posible observar, primero, que la muestra investigada no presenta una presencia significativa del síndrome, de acuerdo con los criterios establecidos por Schaufeli et al. (2002), dado que los promedios de bajo agotamiento y despersonalización, y el alto rendimiento o participación en el trabajo, no representan indicaciones significativas de Burnout. En conclusión, la identificación y el análisis de las dimensiones de la participación en el trabajo, la muestra mostró un indicativo de participación - de acuerdo con Schaufeli y Bakker (2003), cuanto mayor sea el puntaje identificado en vigor, dedicación y absorción, mayor será la participación en el trabajo.

Palabras clave: Síndrome de Burnout; compromiso en el trabajo; Sector de comercio.

\section{Introdução}

Ao falar sobre pesquisas em gestão de pessoas e, mais especificamente, sobre o comportamento do ser humano no ambiente de trabalho, é necessário recordar que existem diversos estudiosos, porém, Martin Seligman foi o estudioso pioneiro na exploração da psicologia positiva com o uso de métodos científicos. A partir do uso de questionários, Seligmann (2002) descobriu que as pessoas mais satisfeitas eram aquelas que tinham descoberto e explorado a sua combinação de forças únicas e marcantes, como humanidade, temperança e persistência.

Desse modo, o tema engajamento no trabalho está vinculado com a preocupação da psicologia positiva em levar em consideração o lado positivo do ser humano e, nesse caso, 
ligado ao comportamento organizacional positivo, está o engajamento no trabalho. Porém, em relação ao trabalho também podem ocorrer o excesso de trabalho, acúmulo de empregos, desequilíbrio entre vida pessoal e profissional, fatores que levam a vida moderna ao estresse, e esse estresse pode, às vezes, alcançar um nível perigoso, levando ao que é denominado de Síndrome de Burnout ou Síndrome do Esgotamento Profissional, que vem do lado mais tradicional da psicologia, levando em consideração que ambientes de trabalho podem ser fonte de sofrimento.

Segundo Maslach (1993), mudanças de comportamento em uma pessoa que começou no trabalho com alegria, com prazer e encantamento pelo trabalho, que passou a se frustrar com a realidade, que está sempre trazendo limites e terminou sobrecarregada, desmotivada e insatisfeita com o trabalho, são o começo do desenvolvimento da Síndrome de Burnout. Em poucas palavras, é o estresse crônico decorrente do trabalho que vai perpetuando e vai fazendo com que o indivíduo mine sua energia e suas expectativas e, na sequência, adoeça (MASLACH, 1993).

Assim, quando o indivíduo demonstra altos níveis de determinação, tenacidade, energia, entusiasmo, orgulho e dedicação ao seu trabalho, esse indivíduo demonstra estar engajado no seu trabalho. Analogicamente, vigor e dedicação são as dimensões centrais do engajamento (SCHAUFELI; BAKKER, 2001). No entanto, vive-se uma crise de engajamento em todo o mundo. Essa afirmativa está de acordo com uma pesquisa feita, recentemente, pelo Instituto Gallup (2017), apontando que 87\% dos funcionários do mundo todo não estão engajados no seu trabalho.

Nesse contexto, o engajamento ocorre quando o indivíduo encontra equilíbrio entre a dimensão de seus desafios e de suas competências, fazendo com que seu nível de produtividade aumente. $\mathrm{O}$ trabalho tem grande influência tanto no que se refere à boa quanto à má qualidade de vida de uma pessoa, mesmo porque não se pode dissociar uma pessoa de seu trabalho, pois a atividade laboral transforma o próprio trabalhador, mesclando-se com sua própria identidade (DEJOURS, 1992; 2004).

Mas, qual a relevância em analisar os níveis de Burnout e o engajamento em funcionários do comércio de uma cidade, em específico, do município de Ijuí? Pelo fato de que a grande maioria de pesquisas e estudos acerca da Síndrome Burnout e Engajamento no Trabalho envolvem somente profissionais de cargos de "alto nível", ou seja, cargos em que há necessidade de, ao menos, uma graduação. Isso se dá pelo fato de que, de acordo com Halabi (2017), apesar de ser encontrado em qualquer área, Burnout se mostra mais evidente 
em pessoas cuja profissão exige envolvimento interpessoal intenso, uma vez que impacta, diretamente, na vida de outras pessoas.

Assim, esta pesquisa tem como objetivo identificar possíveis relações entre as dimensões da Síndrome de Burnout (exaustão emocional, despersonalização e baixa realização profissional) e o Engajamento no Trabalho (vigor, dedicação e absorção) em funcionários do comércio da cidade de Ijuí, localizada no Estado do Rio Grande do Sul. Para tanto, utilizou para mensuração da síndrome de Burnout o instrumento MBI-GS dos autores Maslach e Jackson (1986) e para engajamento no trabalho o UWES dos autores Schaufeli e Bakker (2003).

\section{Referencial Teórico}

\subsection{Síndrome de Burnout}

O termo Síndrome de Burnout surgiu na década de 70 nos Estados Unidos e foi desenvolvido por Freundenberger (1974), que observou, durante um período de um ano, que geralmente muitos dos voluntários com quem trabalhava começavam a apresentar um certo desgaste no humor e desmotivação, apresentando outros sintomas físicos e psíquicos que denotavam um particular estado de exaustão.

Na década de 80, as investigações sobre Síndrome de Burnout se deram nos Estados Unidos e, posteriormente, o conceito começou a ser investigado no Canadá, Inglaterra, França, Alemanha, Israel, Itália, Espanha, Suécia e Polônia. Em cada país, foi adotado e aplicado o instrumento criado nos Estados Unidos, especialmente o Maslach Burnout Inventory, de Maslach e Jackson (MASLACH; SCHAUFELI, 1993). Ainda, a esse instrumento foram incorporadas outras variáveis, satisfação ocupacional, estresse ocupacional, carga de trabalho, demissões, conflito e ambiguidade de papéis e expectativas no emprego. Também, foram investigadas a relação da Síndrome de Burnout com variáveis demográficas como idade, sexo e estado civil.

Tendo em vista que a Síndrome de Burnout origina-se no ambiente organizacional, é importante destacar que o trabalho, com o passar dos anos, vem sofrendo alterações perceptíveis, desde a sua distribuição de poder e a ampliação tecnológica, até suas tarefas rotineiras, práticas e técnicas, que demandam mão de obra cada vez mais qualificada, além de conhecimentos específicos para cada cargo. Com isso, pode-se considerar que o ambiente 
de trabalho possui aspectos que interferem no bem-estar do empregado. Por isso, realizar estudos em ambientes que possam auxiliar os pesquisadores a identificar os fatores capazes de levar o indivíduo a desencadear a Síndrome de Burnout tornou-se extremamente necessário.

O profissional, em seu ambiente organizacional, vivencia, constantemente, situações de estresse. Porém, quando os níveis de tensão, ansiedade, perfeccionismo e competitividade são altos, cada indivíduo responde a essas situações de maneira diferente, e dependendo de fatores organizacionais, individuais, laborais e sociais, o risco de desenvolver sofrimento psíquico, estresse, depressão, Burnout - são maiores (TRIGO; TENG; HALLAK 2007).

\subsection{Engajamento no Trabalho}

O termo Engajamento foi um produto das tentativas do movimento da psicologia positiva em melhorar o local de trabalho e é definido, não como uma condição momentânea, mas como um estado psicológico de experiência de trabalho persistente, refletindo quanto de si mesmo um empregado investe no seu papel no trabalho (KAHN, 1990). Além disso, o engajamento do indivíduo envolve aspectos físicos, cognitivos e emocionais da sua experiência com o trabalho e proporciona sentido à medida com que ele se conecta com seu papel (KAHN, 1990).

Segundo Kahn (1990), pessoas engajadas demonstram maior identificação com o seu trabalho e promovem um estado mental que possibilita a produção de resultados positivos, tanto para o indivíduo (crescimento e desenvolvimento pessoal) quanto para a organização onde trabalha (qualidade do desempenho e produtividade). Maslach e Leiter (1997) destacaram que os indivíduos engajados eram caracterizados por três aspectos principais: energia, envolvimento e eficácia. Esses três aspectos positivos são, simultaneamente, opostos às três dimensões clássicas do conceito de Burnout - exaustão, cinismo e queda no senso de eficácia profissional - e com esta concepção, engajamento no trabalho assumiu um polo oposto ao de Burnout.

Um bom exemplo de um indivíduo altamente engajado com o seu trabalho é aquela situação onde ele está fazendo o que faz de melhor, em torno de pessoas que ele aprecia, resultando em recompensas psicológicas significativas. Engajamento, como um estado psicológico que foi afetado pelo ambiente, reflete sentimentos de empoderamento, envolvimento, afetividade positiva, compromisso, entusiasmo, absorção e conectividade. 
De acordo com Maslach e Leiter (1997), o engajamento é caracterizado por energia, envolvimento e eficácia. Eles afirmam que quando a Síndrome de Burnout se desenvolve, a energia se transforma em exaustão, envolvimento se transforma em cinismo e eficácia se transforma em ineficácia.

\section{Método}

O método adotado utilizou as abordagens qualitativa e quantitativa, objetivos descritivo e explicativo. Foram utilizados como procedimentos técnicos o bibliográfico, o levantamento de dados e a pesquisa de campo, subsidiados pelos dados coletados através de um questionário sociodemográfico, baseado no instrumento MBI-GS (Maslach Burnout Inventory - General Survey) e instrumento UWES (Utrecht Work Engagement Scale).

Os sujeitos da pesquisa são funcionários de estabelecimentos comerciais na cidade de Ijuí. Desse modo, consiste em uma amostra não probabilística por conveniência, formada por sessenta e sete dos funcionários de doze estabelecimentos comerciais na cidade de Ijuí, os quais responderam ao questionário impresso e via formulário do Google Docs. Nesta pesquisa foram utilizados dois instrumentos de pesquisa validados por autores e ainda uma parte para identificação do perfil dos respondentes.

O primeiro questionário utilizado foi o MBI-GS (Maslach Burnout Inventory General Survey), em português, que foi elaborado por Maslach e Jackson (1986). Trata-se de um inventário composto por dezzesseis afirmativas, sendo seis para a dimensão de Exaustão Emocional (EE) (questões 1 a 6), quatro para Despersonalização (DE) (questões 7 a 10) e seis para Realização Profissional (RP) (questões 11 a 16). É um questionário autoaplicável, do tipo Likert de sete pontos que variam de 0= "nunca", 1= "uma vez ao ano ou menos", 2= "uma vez ao mês ou menos", 3 = "algumas vezes ao mês", 4= "uma vez por semana", 5= "algumas vezes por semana", 6= "todos os dias".

O segundo questionário utilizado foi o UWES-17 (Utrecht Work Engagement Scale), em português, o qual foi elaborado por Schaufeli e Bakker (2003). Trata-se de um inventário composto por dezessete afirmativas, sendo seis para vigor (questões: 1, 4, 8, 12, 15 e 17), cinco para dedicação (questões: 2, 5, 7, 10 e 13) e seis para absorção (questões: 3, 6, 9, 11, 14 e 16). É um questionário autoaplicável, do tipo Likert de sete pontos que variam de $0=$ "nunca", 1= "uma vez ao ano ou menos", 2= "uma vez ao mês ou menos", $3=$ "algumas 
vezes ao mês", 4= "uma vez por semana", 5= "algumas vezes por semana", 6= "todos os dias".

Os dados coletados através dos questionários foram, inicialmente, organizados em uma base através do Software Excel e, a partir deste, tabulados e analisados, quantitativamente, para realização da descrição da amostra. Para a descrição do perfil dos respondentes, foi utilizada tabela de frequência.

\section{Discussão e Resultados}

\subsection{Análise do Perfil da Amostra}

Para identificar o perfil sócio demográfico da amostra, foram utilizadas tabelas de frequência. Assim, a amostra foi de sessenta e sete funcionários de doze estabelecimentos comerciais da cidade de Ijuí, conforme demonstra o Quadro 1 a seguir:

\begin{tabular}{|c|c|c|c|}
\hline Variáveis & Alternativas & Frequência & Percentual \\
\hline \multirow{5}{*}{ Ano de admissão na empresa } & Entre 1990 e 2000 & 6 & $8,96 \%$ \\
\hline & Entre 2001 e 2005 & 4 & $5,97 \%$ \\
\hline & Entre 2006 e 2010 & 12 & $17,91 \%$ \\
\hline & Entre 2011 e 2015 & 25 & $37,31 \%$ \\
\hline & Entre 2016 e 2018 & 20 & $29,85 \%$ \\
\hline \multirow{3}{*}{ Gênero } & Masculino & 34 & $50,75 \%$ \\
\hline & Feminino & 33 & $49,25 \%$ \\
\hline & Prefiro Não dizer & 0 & $0,00 \%$ \\
\hline \multirow{6}{*}{ Faixa Etária } & 14 a 20 anos & 9 & $13,43 \%$ \\
\hline & 21 a 26 anos & 13 & $19,40 \%$ \\
\hline & 27 a 33 anos & 22 & $32,84 \%$ \\
\hline & 34 a 46 anos & 9 & $13,43 \%$ \\
\hline & 47 a 55 anos & 7 & $10,45 \%$ \\
\hline & mais de 55 anos & 7 & $10,45 \%$ \\
\hline
\end{tabular}

Quadro 1: Caracterização geral do perfil da Amostra. Fonte: Dados da pesquisa (2018).

Conforme os dados apresentados no Quadro 1 quanto ao ano de admissão da empresa, 8,96\% (seis) dos funcionários foram contratados entre 1990 e 2000, mostrando também um número baixo de respostas os contratados entre 2001 e 2005, esses sendo 5,97\% (quatro). Números mais elevados oriundos das respostas dos contratados entre 2006 e 2010, que são 17,91\% (doze), assim como dos contratados entre 2016 e 2018, que são 29,85\% 
(vinte), e dos contratados entre 2011 e 2015, que são 37,31\% (vinte e cinco), mostrando-se o valor mais elevado de todos. Pode-se dizer, então, que a maioria dos respondentes está entre dois e sete anos na mesma empresa.

Partindo para a variável gênero, 50,75\% (trinta e quatro) dos participantes são do sexo masculino e 49,25\% (trinta e três) são do sexo feminino, demonstrando, assim, um equilíbrio de ambos os gêneros no ramo. Quando perguntados sobre a idade, 20,90\% (quatorze) dos participantes têm quarenta e sete anos de idade ou mais, seguidos por 13,43\% (nove) de participantes que têm entre quatorze e vinte anos de idade, verificando-se o mesmo valor para os de idades entre trinta e quatro e quarenta e seis anos de idade. Os valores mais elevados foram obtidos com os respondentes de idades entre vinte e um e vinte e seis anos, que são $19,40 \%$ (treze) e, por fim, 32,84\% (vinte e dois) dos participantes entre vinte e sete e trinta e três anos de idade, mostrando-se maioria. Nota-se que pessoas mais novas, ou seja, entre quatorze e vinte anos, e pessoas mais velhas, que têm quarenta e sete anos de idade ou mais, são minoria entre os respondentes.

No Quadro 2, os resultados se referem à caracterização do perfil profissional da amostra.

\begin{tabular}{|c|c|c|c|}
\hline Variáveis & Alternativas & Frequência & Percentual \\
\hline \multirow{2}{*}{ Possui cargo de gerência/supervisão } & Sim & 18 & $28,76 \%$ \\
\cline { 2 - 4 } & Não & $\mathbf{4 9}$ & $\mathbf{7 3 , 1 3 \%}$ \\
\hline \multirow{3}{*}{ Carga horária semanal } & Entre 20 e 30 h & 4 & $5,97 \%$ \\
\cline { 2 - 4 } & Entre 31 e 40 h & 16 & $23,88 \%$ \\
\cline { 2 - 4 } & Entre 41 e 50 h & $\mathbf{4 4}$ & $\mathbf{6 5 , 6 7 \%}$ \\
\cline { 2 - 4 } & Entre 51 e 60 h & 3 & $4,47 \%$ \\
\hline \multirow{3}{*}{ Trabalha no turno da noite } & Todos os dias & 6 & $8,96 \%$ \\
\cline { 2 - 4 } & Não & $\mathbf{4 9}$ & $\mathbf{7 3 , 1 3 \%}$ \\
\cline { 2 - 4 } & Às vezes & 12 & $17,91 \%$ \\
\hline \multirow{3}{*}{ Quantas vezes por semana trabalha no turno da noite } & Uma vez & 4 & $5,97 \%$ \\
\cline { 2 - 4 } & Duas vezes & 2 & $2,99 \%$ \\
\cline { 2 - 4 } & Três vezes & 0 & $0,00 \%$ \\
\cline { 2 - 4 } & Quatro vezes & 2 & $2,99 \%$ \\
\cline { 2 - 4 } & Cinco vezes & 3 & $4,48 \%$ \\
\cline { 2 - 4 } & Seis vezes & 3 & $4,48 \%$ \\
\cline { 2 - 4 } & Nunca & $\mathbf{5 3}$ & $\mathbf{7 9 , 1 0 \%}$ \\
\hline \multirow{3}{*}{ Ganha folga no domingo } & Nunca & 0 & $0,00 \%$ \\
\hline \multirow{2}{*}{} & Raramente & 1 & $1,49 \%$ \\
\hline & Geralmente & 3 & $4,48 \%$ \\
\hline
\end{tabular}




\begin{tabular}{|l|c|c|c|}
\hline \multirow{3}{*}{ Faz horas extras } & Sempre & $\mathbf{6 3}$ & $\mathbf{9 4 , 0 3 \%}$ \\
\hline \multirow{3}{*}{ Entra em contato com o consumidor na sua função } & Sempre & 8 & $11,94 \%$ \\
\cline { 2 - 4 } & Geralmente & 11 & $16,42 \%$ \\
\cline { 2 - 4 } & Raramente & $\mathbf{2 4}$ & $\mathbf{3 5 , 8 2 \%}$ \\
\cline { 2 - 4 } & Nunca & $\mathbf{2 4}$ & $\mathbf{3 5 , 8 2 \%}$ \\
\cline { 2 - 4 } & Sim & $\mathbf{5 4}$ & $\mathbf{8 0 , 6 0 \%}$ \\
\hline & Não & 7 & $10,45 \%$ \\
\hline \multirow{2}{*}{ Às vezes } & 6 & $8,96 \%$ \\
\hline
\end{tabular}

Quadro 2: Caracterização do perfil profissional. Fonte: Dados da pesquisa (2018).

Ao observar-se o Quadro 2, nota-se que grande maioria dos respondentes não possui cargo de gerência/supervisão, sendo esses 73,13\% (quarenta e nove); em contrapartida, somente $28,76 \%$ (dezoito) responderam possuir cargo de gerência/supervisão.

Quando perguntados sobre sua carga horária semanal, a maioria encontra-se na faixa entre quarenta e uma e cinquenta horas semanais, sendo esses $65,67 \%$ (quarenta e quatro) do total. O segundo valor mais elevado é $23,88 \%$ (dezesseis) dos que trabalham entre trinta e uma e quarenta horas semanais, seguido por 5,97\% (quatro), cuja carga horária semanal é entre vinte e trinta horas e, por fim, 4,47\% (três), que trabalham de cinquenta e uma a sessenta horas semanais. Do total de respondentes, 73,13\% (quarenta e nove) não trabalham no turno da noite, $17,91 \%$ (doze) trabalham no turno da noite às vezes e $8,96 \%$ (seis) trabalham no turno da noite todos os dias, sendo que, destes, 5,97\% (quatro) trabalham uma vez na semana no turno da noite, $8,96 \%$ (seis) trabalham cinco ou seis vezes na semana no turno da noite e $6 \%$ (quatro) trabalham duas ou quatro vezes na semana no turno da noite.

Entre os sessenta e sete respondentes, quando perguntados com que frequência ganham folga no domingo, 94,03\% (sessenta e três) deles responderam "sempre", tendo apenas 4,48\% (três) que, geralmente, ganham folga no domingo, seguido de 1,49\% (um) que raramente ganha folga no domingo. Por fim, quando questionados sobre a frequência com que fazem horas extras, igualmente foram respondidas as alternativas "raramente" e "nunca" com incidência de $35,82 \%$ (vinte e quatro), restando $16,42 \%$ (onze) dos que responderam fazer horas extras geralmente e $11,94 \%$ (oito) que fazem horas extras sempre. De um total de sessenta e sete respondentes, 80,60\% deles (cinquenta e quatro) têm contato direto com o consumidor, enquanto $10,45 \%$ (sete) não têm nenhum e $8,96 \%$ (seis) têm contato com o consumidor às vezes. 


\subsection{Análise da incidência das dimensões de Engajamento no Trabalho - vigor, dedicação e absorção}

A primeira dimensão para mensuração do Engajamento no Trabalho é o vigor, que, de acordo com Bakker e Schaufeli (2002), se caracteriza por altos níveis de energia, persistência, desejo de se esforçar no trabalho e resiliência mental nas atividades laborais, e tem sua frequência apresentada nos Quadros 3 e 4 . O Quadro 5 expõe a frequência de cada questão que engloba a dimensão.

\begin{tabular}{|c|c|c|c|c|c|c|}
\hline \multicolumn{7}{|c|}{ Alternativas } \\
\hline 0 & 1 & 2 & 3 & 4 & 5 & 6 \\
\hline \multicolumn{7}{|c|}{ Variáveis } \\
\hline \multicolumn{7}{|c|}{1 - Em meu trabalho, sinto-me repleto (cheio) de energia. } \\
\hline $0 \%$ & $0 \%$ & $5,97 \%$ & $13,43 \%$ & $5,97 \%$ & $43,28 \%$ & $31,34 \%$ \\
\hline \multicolumn{7}{|c|}{4 - No trabalho, sinto-me com força e vigor (vitalidade). } \\
\hline $0 \%$ & $1,49 \%$ & $13,43 \%$ & $8,96 \%$ & $11,94 \%$ & $34,33 \%$ & $29,85 \%$ \\
\hline \multicolumn{7}{|c|}{8 - Quando me levanto pela manhã, tenho vontade de ir trabalhar. } \\
\hline $4,48 \%$ & $2,99 \%$ & $7,46 \%$ & $11,94 \%$ & $8,96 \%$ & $29,85 \%$ & $34,33 \%$ \\
\hline \multicolumn{7}{|c|}{12 - Posso continuar trabalhando durante longos períodos de tempo. } \\
\hline $1,49 \%$ & $4,48 \%$ & $8,96 \%$ & $4,48 \%$ & $11,94 \%$ & $29,85 \%$ & $38,81 \%$ \\
\hline \multicolumn{7}{|c|}{15 - Em meu trabalho, sou uma pessoa mentalmente resiliente (versátil). } \\
\hline $0 \%$ & $0 \%$ & $1,49 \%$ & $5,97 \%$ & $10,45 \%$ & $29,85 \%$ & $52,24 \%$ \\
\hline \multicolumn{7}{|c|}{17 - No trabalho, sou persistente mesmo quando as coisas não vão bem. } \\
\hline $0 \%$ & $0 \%$ & $1,49 \%$ & $8,96 \%$ & $10,45 \%$ & $31,34 \%$ & $47,76 \%$ \\
\hline
\end{tabular}

Quadro 3: Frequência da dimensão vigor. Fonte: Dados da Pesquisa (2018).

Em análise à questão 15 , “em meu trabalho, sou uma pessoa mentalmente resiliente (versátil)", que apresenta o maior valor encontrado da dimensão vigor na amostra, pode-se observar um resultado positivo, com valor de 50,28\% de resposta para a alternativa 6 "Sempre; Todos os dias", que é a alternativa de maior peso na dimensão. O segundo maior valor encontrado na dimensão vem da questão 17 , "No trabalho, sou persistente mesmo quando as coisas não vão bem", com frequência de 47,76\% para a alternativa 6 "Sempre; Todos os dias", seguida da questão 1, "Em meu trabalho, sinto-me repleto (cheio) de energia", com 43,28\% para a alternativa 5, "Quase sempre; algumas vezes por semana", que é a alternativa de segundo maior peso na dimensão. Os demais valores encontrados são na questão 12, "Posso continuar trabalhando durante longos períodos de tempo", com 38,81\% para a alternativa 6 "Sempre; Todos os dias", na questão 8, "Quando me levanto pela manhã, tenho vontade de ir trabalhar", com 34,33\% para a alternativa 6 "Sempre; Todos os dias", e, 
por fim, o valor mais baixo obtido para a dimensão vigor encontra-se na questão 4, "No trabalho, sinto-me com força e vigor (vitalidade)", com 34,33\% para a alternativa 5, "Quase sempre; algumas vezes por semana".

A incidência da dimensão vigor na amostra é apresentada a seguir, no Quadro 4.

\begin{tabular}{|c|l|c|}
\hline Questão & \multicolumn{1}{|c|}{ Vigor } & Incidência \\
\hline $\mathbf{1}$ & Em meu trabalho, sinto-me repleto (cheio) de energia. & $80,09 \%$ \\
\hline $\mathbf{4}$ & No trabalho, sinto-me com força e vigor (vitalidade). & $75,62 \%$ \\
\hline $\mathbf{8}$ & Quando me levanto pela manhã, tenho vontade de ir trabalhar. & $74,13 \%$ \\
\hline $\mathbf{1 2}$ & Posso continuar trabalhando durante longos períodos de tempo. & $77,61 \%$ \\
\hline $\mathbf{1 5}$ & Em meu trabalho, sou uma pessoa mentalmente resiliente (versátil). & $\mathbf{8 7 , 5 6 \%}$ \\
\hline $\mathbf{1 7}$ & No trabalho, sou persistente mesmo quando as coisas não vão bem. & $85,82 \%$ \\
\hline
\end{tabular}

Quadro 4: Incidência da dimensão vigor na amostra. Fonte: Dados da pesquisa (2018).

Em análise ao Quadro 4, pode-se notar que, dentre as seis questões que englobam a dimensão, a que demonstrou maior incidência de Vigor na amostra foi a questão 15: "Em meu trabalho, sou uma pessoa mentalmente resiliente (versátil)", com valor de 87,56\%, seguida da questão 17: "No trabalho, sou persistente mesmo quando as coisas não vão bem", com incidência de 85,82\%, e da questão 1: "Em meu trabalho, sinto-me repleto (cheio) de energia" com 80,09\% de incidência e, da questão 12: "Posso continuar trabalhando durante longos períodos de tempo", com 77,61\% de incidência. Os valores mais baixos vêm das questões 4: "No trabalho, sinto-me com força e vigor (vitalidade)", com 75,62\% de incidência, e 8: “Quando me levanto pela manhã, tenho vontade de ir trabalhar", com 74,13\% de incidência. A incidência total da dimensão vigor na amostra é de 80,14\% e, conforme Shaufeli e Bakker, (2003) quanto mais alto o escore identificado em vigor, mais alto o nível de energia no trabalho.

A segunda dimensão do Engajamento no Trabalho é a dedicação, que consiste em um estado de concentração integral na realização do trabalho; sensação de se deixar levar pelo trabalho, objetivo de realização, inspiração e orgulho; desafio; ver significado nas atividades realizadas e entusiasmo (BAKKER et al., 2008).

No Quadro 5, são apresentados os valores obtidos da dimensão Dedicação.

\begin{tabular}{|c|c|c|c|c|c|c|}
\hline \multicolumn{7}{|c|}{ Alternativas } \\
\hline $\mathbf{0}$ & $\mathbf{1}$ & $\mathbf{2}$ & $\mathbf{3}$ & $\mathbf{4}$ & $\mathbf{5}$ & $\mathbf{6}$ \\
\hline \multicolumn{7}{|c|}{ Variáveis } \\
\hline $0 \%$ & 2 - Eu acho que o trabalho que realizo é cheio de significado e propósito. \\
\hline
\end{tabular}




\begin{tabular}{|c|c|c|c|c|c|c|}
\hline \multicolumn{7}{|c|}{5 - Estou entusiasmado com meu trabalho. } \\
\hline $0 \%$ & $8,96 \%$ & $5,97 \%$ & $10,45 \%$ & $7,46 \%$ & $28,36 \%$ & $\mathbf{3 8 , 8 1 \%}$ \\
\hline $2,99 \%$ & $7,46 \%$ & $5,97 \%$ & $8,96 \%$ & $10,45 \%$ & $28,36 \%$ & $\mathbf{3 5 , 8 2 \%}$ \\
\hline \multicolumn{7}{|c|}{7 - Meu trabalho me inspira. } \\
\hline $0 \%$ & $4,48 \%$ & $7,46 \%$ & $4,48 \%$ & $7,46 \%$ & $31,34 \%$ & \multirow{4}{*}{$\mathbf{4 4 , 7 8 \%}$} \\
\hline $0 \%$ & $4,48 \%$ & $7,46 \%$ & $11,94 \%$ & $17,91 \%$ & $14,93 \%$ & \multirow{4}{*}{$\mathbf{4 3 , 2 8 \%}$} \\
\hline
\end{tabular}

Quadro 5: Frequência da dimensão dedicação. Fonte: Dados da Pesquisa (2018).

Ao analisar-se o Quadro 5, pode-se identificar que todas as respostas de maior valor provêm da alternativa de maior peso (alternativa 6 "Sempre; Todos os dias"). O maior valor encontrado é na questão 2: "Eu acho que o trabalho que realizo é cheio de significado e propósito", com 50,75\% de frequência para a alternativa 6, seguida da questão 10: "Estou orgulhoso com o trabalho que realizo", com 44,78\% de frequência, da questão 13: "Para mim meu trabalho é desafiador", com 43,28\%, da questão 5: "Estou entusiasmado com meu trabalho", com $38,81 \%$ e, por fim, da questão com menor valor, de $35,82 \%$, sendo a questão 7: "Meu trabalho me inspira". O Quadro 6 serve para apresentar a incidência da dimensão Dedicação.

\begin{tabular}{|c|l|c|}
\hline Questão & \multicolumn{1}{|c|}{ Dedicação } & Incidência \\
\hline $\mathbf{2}$ & Eu acho que o trabalho que realizo é cheio de significado e propósito. & $\mathbf{8 3 , 8 3 \%}$ \\
\hline $\mathbf{5}$ & Estou entusiasmado com meu trabalho. & $76,12 \%$ \\
\hline $\mathbf{7}$ & Meu trabalho me inspira. & $74,12 \%$ \\
\hline $\mathbf{1 0}$ & Estou orgulhoso com o trabalho que realizo. & $81,34 \%$ \\
\hline $\mathbf{1 3}$ & Para mim meu trabalho é desafiador. & $76,86 \%$ \\
\hline
\end{tabular}

Quadro 6: Incidência da dimensão dedicação na amostra. Fonte: Dados da Pesquisa (2018).

Como exposto no Quadro 6, dentre as cinco questões que englobam a dimensão, a que demonstrou maior incidência de Dedicação na amostra foi a questão 2: "Eu acho que o trabalho que realizo é cheio de significado e propósito", com valor de 83,83\%, seguida da questão 10: "Estou orgulhoso com o trabalho que realizo", com incidência de 81,34\%, e da questão 13: "Para mim meu trabalho é desafiador", com 76,86\% de incidência. Os valores mais baixos vêm das questões 5: "Estou entusiasmado com meu trabalho", com 76,12\% de incidência, e 7: "Meu trabalho me inspira", com 74,12\% de incidência. A incidência total da dimensão dedicação na amostra é de 78,45\%. 
O Quadro 7, a seguir, apresenta a frequência da terceira dimensão do Engajamento no Trabalho: a absorção, que "implica estar plenamente concentrado e feliz na realização do trabalho; sensação de que o tempo passa "voando" e "dificuldade em se desligar do trabalho" (BAKKER et al., 2008).

\begin{tabular}{|c|c|c|c|c|c|c|}
\hline \multicolumn{7}{|c|}{ Alternativas } \\
\hline $\mathbf{0}$ & 1 & 2 & 3 & 4 & 5 & 6 \\
\hline \multicolumn{7}{|c|}{ Variáveis } \\
\hline \multicolumn{7}{|c|}{3 - O "tempo voa" quando estou trabalhando } \\
\hline $0 \%$ & $1,49 \%$ & $0 \%$ & $13,43 \%$ & $8,96 \%$ & 32,84 & $43,28 \%$ \\
\hline \multicolumn{7}{|c|}{6 - Quando estou trabalhando, esqueço tudo o que se passa ao meu redor. } \\
\hline $7,46 \%$ & $4,48 \%$ & $7,46 \%$ & $7,46 \%$ & $19,40 \%$ & $23,88 \%$ & $29,85 \%$ \\
\hline \multicolumn{7}{|c|}{9 - Sinto-me feliz quando trabalho intensamente } \\
\hline $1,49 \%$ & $2,99 \%$ & $5,97 \%$ & $5,97 \%$ & $5,97 \%$ & $38,81 \%$ & $38,81 \%$ \\
\hline \multicolumn{7}{|c|}{11 - Sinto-me envolvido com o trabalho que faço. } \\
\hline $0 \%$ & $0 \%$ & $5,97 \%$ & $5,97 \%$ & $5,97 \%$ & $29,85 \%$ & $52,24 \%$ \\
\hline \multicolumn{7}{|c|}{14 - "Deixo-me levar" pelo meu trabalho } \\
\hline $0 \%$ & $7,46 \%$ & $7,46 \%$ & $8,96 \%$ & $22,39 \%$ & $14,93 \%$ & $38,81 \%$ \\
\hline \multicolumn{7}{|c|}{16 - É difícil desligar-me do trabalho. } \\
\hline $2,99 \%$ & $10,45 \%$ & $11,94 \%$ & $16,42 \%$ & $17,91 \%$ & $17,91 \%$ & $22,39 \%$ \\
\hline
\end{tabular}

Quadro 7: Frequência da dimensão absorção. Fonte: Dados da Pesquisa (2018).

Tendo a análise iniciada pela questão em que se obteve o maior valor, sendo a questão 11: "Sinto-me envolvido com o trabalho que faço", nota-se uma frequência de 52,24\% de respostas para a alternativa 6 "Sempre; Todos os dias". O segundo maior valor encontrado é apontado pela questão 3: "O tempo voa quando estou trabalhando", com frequência de 43,28\% também para a alternativa 6 "Sempre; Todos os dias", seguida da questão 14: "Deixo-me levar pelo trabalho" com frequência de 38,81\% para a alternativa 6 "Sempre; Todos os dias", e da questão 9: "Sinto-me feliz quando trabalho intensamente", com frequência de 38,81\% para ambas alternativas 5 "Quase sempre; algumas vezes por semana" e 6 "Sempre; Todos os dias". Os valores mais baixos de frequência estão na questão 6: "Quando estou trabalhando, esqueço tudo o que se passa ao meu redor", com frequência de 29,85\% para a alternativa 6 "Sempre; Todos os dias", e na questão 16: "É difícil desligarme do trabalho", com frequência de $22,39 \%$ para a alternativa 6 "Sempre; Todos os dias", obtendo, também, valores significativos para a alternativa 5 "Quase sempre; algumas vezes por semana" $(17,91 \%)$, assim como para as alternativas 4 "Frequentemente; uma vez por semana" $(17,91 \%)$ e 3 "Regularmente; algumas vezes por mês" $(16,42 \%)$. 
Finalmente, no Quadro 8, são especificadas as incidências da dimensão absorção na amostra.

\begin{tabular}{|c|l|c|}
\hline Questão & \multicolumn{1}{c|}{ Absorção } & Incidência \\
\hline $\mathbf{3}$ & O “tempo voa” quando estou trabalhando. & $83,58 \%$ \\
\hline $\mathbf{6}$ & Quando estou trabalhando, esqueço tudo o que se passa ao meu redor. & $69,65 \%$ \\
\hline $\mathbf{9}$ & Sinto-me feliz quando trabalho intensamente. & $80,60 \%$ \\
\hline $\mathbf{1 1}$ & Sinto-me envolvido com o trabalho que faço. & $\mathbf{8 6 , 0 7 \%}$ \\
\hline $\mathbf{1 4}$ & "Deixo-me levar” pelo meu trabalho. & $74,38 \%$ \\
\hline $\mathbf{1 6}$ & É difícil desligar-me do trabalho. $\quad$ Total & $75,62 \%$ \\
\hline
\end{tabular}

Quadro 8: Incidência da dimensão absorção na amostra. Fonte: Dados da Pesquisa (2018).

Ao observar-se o Quadro 8, nota-se que a variável de maior incidência na amostra, dentro do espectro da dimensão absorção, foi a da questão 11: "Sinto-me envolvido com o trabalho que faço", com incidência de $86,07 \%$, seguida da questão 3 : "O "tempo voa" quando estou trabalhando", com incidência de 83,58\%, e da questão 9: "Sinto-me feliz quando trabalho intensamente", com incidência de 80,60\%. Valores relativamente mais baixos foram encontrados na questão 16: "É difícil desligar-me do trabalho", com incidência de 75,62\%; na questão 14: "Deixo-me levar" pelo meu trabalho", com incidência de 74,38\% e, representando o valor mais baixo dentre todas as variáveis, na questão 6: "Quando estou trabalhando, esqueço tudo o que se passa ao meu redor", com incidência de $69,65 \%$. A incidência total da dimensão do Engajamento no Trabalho absorção na amostra é de 78,32\%, demonstrando ser a dimensão que possui menor incidência na amostra.

Aqueles que apresentam altos escores, sentem-se envolvidos e imersos no trabalho, têm dificuldade em desapegar-se e esquecem tudo à sua volta, parecendo que o tempo voa quando estão trabalhando, são caracterizados pela concentração total em seu trabalho, em que o tempo passa depressa, e encontram dificuldades em desapegar-se do trabalho (SCHAUFELI; BAKKER, 2003).

Pode-se concluir que a amostra em questão apresenta alto Engajamento no Trabalho, levando em consideração que Schaufeli e Bakker (2003) afirmam que, quanto mais alta a incidência de vigor, dedicação e absorção, maior será o engajamento no trabalho. Nesse grupo, a dimensão vigor apresentou incidência de 80,14\%; a segunda dimensão, dedicação, na amostra em questão, obteve incidência de 78,45\%; na terceira dimensão, absorção apresentou $78,32 \%$. 


\subsection{Análise da incidência das dimensões da Síndrome de Burnout - exaustão emocional (EE), despersonalização (DP) e realização profissional (RP)}

A primeira dimensão para mensuração da Síndrome de Burnout é a exaustão emocional (EE), que, segundo (MASLACH et al., 1997), refere-se à diminuição de energia nas atividades laborais e ao sentimento de esgotamento físico e psíquico, e tem sua frequência apresentada nos quadros 9 e 10.

O quadro 9 expõe a frequência de cada questão que engloba a dimensão.

\begin{tabular}{|c|c|c|c|c|c|c|}
\hline \multicolumn{7}{|c|}{ Alternativas } \\
\hline $\mathbf{0}$ & 1 & 2 & 3 & 4 & 5 & 6 \\
\hline \multicolumn{7}{|c|}{ Variáveis } \\
\hline \multicolumn{7}{|c|}{1 Sinto-me esgotado/a emocionalmente por meu trabalho. } \\
\hline $17,91 \%$ & $17,91 \%$ & $13,43 \%$ & $19,40 \%$ & $11,94 \%$ & $14,94 \%$ & $4,48 \%$ \\
\hline \multicolumn{7}{|c|}{2 Sinto-me cansado/a ao final de um dia de trabalho. } \\
\hline $20,90 \%$ & $7,46 \%$ & $16,42 \%$ & $7,46 \%$ & $7,46 \%$ & $22,39 \%$ & $17,91 \%$ \\
\hline \multicolumn{7}{|c|}{3 Quando me levanto pela manhã e vou enfrentar outra jornada de trabalho, sinto-me cansado/a. } \\
\hline $38,81 \%$ & $17,91 \%$ & $7,46 \%$ & $16,42 \%$ & $0 \%$ & $13,43 \%$ & $5,97 \%$ \\
\hline \multicolumn{7}{|c|}{4 Trabalhar o dia todo é realmente motivo de tensão para mim. } \\
\hline $49,25 \%$ & $10,45 \%$ & $14,93 \%$ & $10,45 \%$ & $4,48 \%$ & $5,97 \%$ & $4,48 \%$ \\
\hline \multicolumn{7}{|c|}{5 Sinto-me acabado por causa do meu trabalho. } \\
\hline $53,73 \%$ & $11,94 \%$ & $8,96 \%$ & $10,45 \%$ & $1,49 \%$ & $8,96 \%$ & $4,48 \%$ \\
\hline \multicolumn{7}{|c|}{6 Só desejo fazer meu trabalho e não ser incomodado. } \\
\hline $26,87 \%$ & $10,45 \%$ & $4,48 \%$ & $13,43 \%$ & $5,97 \%$ & $8,96 \%$ & $29,85 \%$ \\
\hline
\end{tabular}

Quadro 9: Frequência da dimensão exaustão emocional. Fonte: Dados da Pesquisa (2018).

Em análise ao Quadro 9, mais especificamente em relação à variável 1, "Sinto-me esgotado/a emocionalmente por meu trabalho", nota-se uma frequência máxima de 19,40\%, para a alternativa 3 "Algumas vezes ao mês". A variável 2, "Sinto-me cansado/a ao final de um dia de trabalho", apresenta uma frequência de valor máximo de 22,39\% para a alternativa 5 “Algumas vezes por semana". As variáveis 3, "Quando me levanto pela manhã e vou enfrentar outra jornada de trabalho, sinto-me cansado/a", 4, "Trabalhar o dia todo é realmente motivo de tensão para mim", e 5, "Sinto-me acabado por causa do meu trabalho", apresentam alta frequência para a alternativa 0 "Nunca", sendo elas, respectivamente, $38,81 \%, 49,25 \%$ e 53,73\%. Por fim, e diferentemente das demais, a variável 6, "Só desejo fazer meu trabalho e não ser incomodado", tem seu valor máximo explicitado na alternativa 6 "Sempre", valor este sendo $29,85 \%$. 
A incidência da dimensão na amostra é apresentada no quadro a seguir, no Quadro 10.

\begin{tabular}{|c|l|c|}
\hline Questão & \multicolumn{1}{|c|}{ EE } & Incidência \\
\hline $\mathbf{1}$ & Sinto-me esgotado/a emocionalmente por meu trabalho. & $34,57 \%$ \\
\hline $\mathbf{2}$ & Sinto-me cansado/a ao final de um dia de trabalho & $\mathbf{5 2 , 1 0 \%}$ \\
\hline $\mathbf{3}$ & $\begin{array}{l}\text { Quando me levanto pela manhã e vou enfrentar outra jornada de trabalho, } \\
\text { sinto-me cansado/a }\end{array}$ & $30,85 \%$ \\
\hline $\mathbf{4}$ & Trabalhar o dia todo é realmente motivo de tensão para mim & $24,38 \%$ \\
\hline $\mathbf{5}$ & Sinto-me acabado por causa do meu trabalho & $23,13 \%$ \\
\hline $\mathbf{6}$ & Só desejo fazer meu trabalho e não ser incomodado & $51,24 \%$ \\
\hline
\end{tabular}

Quadro 10 - Incidência da dimensão exaustão emocional na amostra. Fonte: Dados da pesquisa (2018).

Em análise ao Quadro 10, pode-se notar que, dentre as seis questões que englobam a dimensão, a que demonstrou maior incidência de EE na amostra foi a questão 2, "Sinto-me cansado/a ao final de um dia de trabalho", com valor de 52,10\%, seguida da questão 6, "Só desejo fazer meu trabalho e não ser incomodado", com incidência de 51,24\%. As questões que apresentam valores de incidência mais baixos são: questão 1, "Sinto-me esgotado/a emocionalmente por meu trabalho", com 34,57\% de incidência, questão 3, "Quando me levanto pela manhã e vou enfrentar outra jornada de trabalho, sinto-me cansado/a”, com $30,85 \%$ de incidência, e questão 4, "Trabalhar o dia todo é realmente motivo de tensão para mim", com $24,38 \%$ de incidência. O valor mais baixo de incidência da dimensão é encontrado na questão 5, "Sinto-me acabado por causa do meu trabalho", com 23,13\% de incidência. A incidência total da dimensão EE na amostra é de 37,27\%.

A segunda dimensão para mensuração da Síndrome de Burnout é a despersonalização (DP), que se caracteriza pela alteração da personalidade do indivíduo, obrigando-o a agir friamente e impessoalmente frente aos demais colegas. O Quadro 11 expõe a frequência de cada questão que engloba a dimensão.

\begin{tabular}{|c|c|c|c|c|c|c|}
\hline \multicolumn{7}{|c|}{ Alternativas } \\
\hline $\mathbf{0}$ & 1 & 2 & 3 & 4 & 5 & 6 \\
\hline \multicolumn{7}{|c|}{ Variáveis } \\
\hline \multicolumn{7}{|c|}{7 Tornei-me menos interessado no meu trabalho desde que assumi esse cargo } \\
\hline $65,67 \%$ & $5,97 \%$ & $2,99 \%$ & $8,96 \%$ & $1,49 \%$ & $8,96 \%$ & $5,97 \%$ \\
\hline \multicolumn{7}{|c|}{8 Tornei-me menos entusiasmado com o meu trabalho. } \\
\hline $\mathbf{5 0 , 7 5 \%}$ & $14,93 \%$ & $5,97 \%$ & $14,93 \%$ & $2,99 \%$ & $7,46 \%$ & $2,99 \%$ \\
\hline \multicolumn{7}{|c|}{9 Tornei-me mais descrente sobre se o meu trabalho contribui para algo. } \\
\hline $59,70 \%$ & $1,49 \%$ & $7,46 \%$ & $10,45 \%$ & $5,97 \%$ & $10,45 \%$ & $4,48 \%$ \\
\hline
\end{tabular}




\begin{tabular}{|c|c|c|c|c|c|c|}
\hline $\mathbf{6 5 , 6 7 \%}$ & $11,94 \%$ & $2,99 \%$ & $10,45 \%$ & $4,48 \%$ & $2,99 \%$ & $1,49 \%$ \\
\hline
\end{tabular}

Conforme apresentado no Quadro 11, as variáveis 7 "Tornei-me menos interessado no meu trabalho desde que assumi esse cargo" e 10 "Duvido da importância do meu trabalho", apresentam a frequência de maior valor dentre as alternativas, valor este sendo $65,67 \%$, atribuído à mesma alternativa 0 "Nunca". O segundo maior valor pode ser notado na variável 9, "Tornei-me mais descrente sobre se o meu trabalho contribui para algo", com frequência de 59,70\% também para a alternativa 0 "Nunca". A variável que apresenta menor valor é a alternativa 8, "Tornei-me menos entusiasmado com o meu trabalho", com frequência $50,75 \%$ para a alternativa 0 "Nunca".

A incidência da dimensão despersonalização na amostra é apresentada no Quadro 12 a seguir.

\begin{tabular}{|c|l|c|}
\hline Questão & \multicolumn{1}{c|}{ DP } & Incidência \\
\hline $\mathbf{7}$ & Tornei-me menos interessado no meu trabalho desde que assumi esse cargo. & $20,89 \%$ \\
\hline $\mathbf{8}$ & Tornei-me menos entusiasmado com o meu trabalho. & $23,13 \%$ \\
\hline $\mathbf{9}$ & Tornei-me mais descrente sobre se o meu trabalho contribui para algo. & $\mathbf{2 5 , 1 2 \%}$ \\
\hline $\mathbf{1 0}$ & Duvido da importância do meu trabalho. & $15,17 \%$ \\
\hline
\end{tabular}

Quadro 12: Incidência da dimensão despersonalização na amostra. Fonte: Dados da pesquisa (2018).

O quadro anterior aponta que a variável que possui maior incidência de despersonalização na amostra é a variável 9, “Tornei-me mais descrente sobre se o meu trabalho contribui para algo", com incidência de 25,12\%, seguida da variável 8, "Tornei-me menos entusiasmado com o meu trabalho", com incidência de despersonalização na amostra de $23,13 \%$. As questões que apresentam menor valor de incidência da dimensão na amostra são as questões 7, "Tornei-me menos interessado no meu trabalho desde que assumi esse cargo", com incidência de 20,89\%, e 10, "Duvido da importância do meu trabalho", com incidência de $15,17 \%$ na amostra. A incidência total da dimensão despersonalização na amostra é de $21,08 \%$.

No Quadro 13, a seguir, são apresentados os dados coletados acerca da terceira dimensão da Síndrome de Burnout: a realização profissional. Maslach, Schaufeli e Leiter (2001) afirmam que se caracteriza por um sentimento de desventura, de insatisfação com suas atividades, de fracasso e de desmotivação. O desejo de abandono do trabalho surge 
gradualmente e esse sentimento afeta a produtividade do trabalhador, interferindo no alcance das metas e objetivos da organização.

\begin{tabular}{|c|c|c|c|c|c|c|}
\hline \multicolumn{7}{|c|}{ Alternativas } \\
\hline $\mathbf{0}$ & 1 & 2 & 3 & 4 & 5 & 6 \\
\hline \multicolumn{7}{|c|}{ Variáveis } \\
\hline \multicolumn{7}{|c|}{1 Sinto-me entusiasmado quando realizo algo no meu trabalho. } \\
\hline $1,49 \%$ & $4,48 \%$ & $1,49 \%$ & $7,46 \%$ & $5,97 \%$ & $28,36 \%$ & $\mathbf{5 0 , 7 5 \%}$ \\
\hline \multicolumn{7}{|c|}{12 Realizei muitas coisas valiosas no meu trabalho. } \\
\hline $0 \%$ & $4,48 \%$ & $4,48 \%$ & $11,94 \%$ & $2,99 \%$ & $31,34 \%$ & $44,78 \%$ \\
\hline \multicolumn{7}{|c|}{13 Posso efetivamente solucionar os problemas que surgem no meu trabalho. } \\
\hline $0 \%$ & $0 \%$ & $1,49 \%$ & $5,97 \%$ & $5,97 \%$ & $28,36 \%$ & $58,21 \%$ \\
\hline \multicolumn{7}{|c|}{14 Sinto que estou dando uma contribuição efetiva para essa organização. } \\
\hline $1,49 \%$ & $0 \%$ & $1,49 \%$ & $5,97 \%$ & $2,99 \%$ & $17,91 \%$ & $70,15 \%$ \\
\hline \multicolumn{7}{|c|}{$15 \mathrm{Na}$ minha opinião, sou bom no que faço. } \\
\hline $0 \%$ & $0 \%$ & $0 \%$ & $4,48 \% \%$ & $4,48 \%$ & $23,88 \%$ & $67,16 \%$ \\
\hline \multicolumn{7}{|c|}{16 No meu trabalho, me sinto confiante de que sou eficiente e capaz de fazer com que as coisas } \\
\hline $0 \%$ & $0 \%$ & $2,99 \%$ & $2,99 \%$ & $4,48 \%$ & $16,42 \%$ & $73,13 \%$ \\
\hline
\end{tabular}

Quadro 13: Frequência da dimensão realização profissional (RP). Fonte: Dados da Pesquisa (2018).

Segundo o Quadro 13, a variável que apresenta maior incidência da dimensão na amostra é a variável 16, "No meu trabalho, me sinto confiante de que sou eficiente e capaz de fazer com que as coisas aconteçam", com frequência de 73,13\% na alternativa 6 "Todos os dias", seguida da variável 14, "Sinto que estou dando uma contribuição efetiva para essa organização", com frequência de 70,15\%, e variável 15, "Na minha opinião, sou bom no que faço", com frequência de 67,16\%, ambas, também, na alternativa 6, “Todos os dias". Assim como as anteriores, todas as outras variáveis têm suas frequências na alternativa 6, "Todos os dias", sendo elas: 58,21\% para a variável 13, "Posso efetivamente solucionar os problemas que surgem no meu trabalho", 50,75\% para a variável 11, "Sinto-me entusiasmado quando realizo algo no meu trabalho" e, como menor valor apontado, 44,78\% para a variável 12 "Realizei muitas coisas valiosas no meu trabalho".

A incidência da dimensão realização profissional na amostra é apresentada no Quadro 14, a seguir.

\begin{tabular}{|c|l|c|}
\hline Questão & \multicolumn{1}{c}{ RP } & Incidência \\
\hline $\mathbf{1 1}$ & Sinto-me entusiasmado quando realizo algo no meu trabalho & $83,33 \%$ \\
\hline $\mathbf{1 2}$ & Realizei muitas coisas valiosas no meu trabalho & $81,09 \%$ \\
\hline $\mathbf{1 3}$ & Posso efetivamente solucionar os problemas que surgem no meu trabalho & $89,30 \%$ \\
\hline
\end{tabular}




\begin{tabular}{|c|l|c|}
\hline $\mathbf{1 4}$ & Sinto que estou dando uma contribuição efetiva para essa organização & $90,55 \%$ \\
\hline $\mathbf{1 5}$ & Na minha opinião, sou bom no que faço & $\mathbf{9 2 , 2 9 \%}$ \\
\hline $\mathbf{1 6}$ & $\begin{array}{l}\text { No meu trabalho, me sinto confiante de que sou eficiente e capaz de fazer } \\
\text { com que as coisas aconteçam }\end{array}$ & $\mathbf{9 2 , 2 9 \%}$ \\
\hline
\end{tabular}

Quadro 14: Incidência da dimensão realização profissional na amostra. Fonte: Dados da pesquisa (2018).

O Quadro 14 apresenta as variáveis 15, "Na minha opinião, sou bom no que faço", e 16, "No meu trabalho, me sinto confiante de que sou eficiente e capaz de fazer com que as coisas aconteçam", como sendo as que apresentam maior incidência, dentre todas as variáveis da dimensão realização profissional na amostra, ambas com mesmo valor de 92,29\%. O segundo valor mais elevado encontra-se na variável 14, "Sinto que estou dando uma contribuição efetiva para essa organização", com incidência de 90,55\%, seguida da variável 13, "Posso efetivamente solucionar os problemas que surgem no meu trabalho", com incidência de 89,30\%, e da variável 11, "Sinto-me entusiasmado quando realizo algo no meu trabalho", com incidência de 83,33\%. O menor valor obtido é encontrado na variável 12, "Realizei muitas coisas valiosas no meu trabalho", com incidência de 81,09\%. A incidência total da dimensão Realização Profissional na amostra é de 88,14\%.

Conforme o modelo de Burnout de Maslach e Jackson (1986), a exaustão é a primeira dimensão a surgir, como indicativo da síndrome, e nessa amostra há frequência de 37,27\%, que pode ser considerado indicativo de um nível da Síndrome Burnout não significativo. A segunda dimensão do modelo de Burnout diz respeito à despersonalização, a qual obteve frequência de $21,08 \%$, representando também indicativo de nível baixo. Por fím, a realização profissional apresentou um valor da frequência de 88,14\%, considerado valor alto, demonstrando alta realização profissional da amostra em seu trabalho.

Tendo em vista os resultados obtidos, considera-se que a amostra em questão não apresenta a Síndrome de Burnout a um nível significativo, pois segundo Schaufeli et al. (2002), frequências baixas de exaustão e despersonalização, e altas de realização ou envolvimento no trabalho, não representam indicativos de Burnout. No entanto, ainda é importante que os superiores/gestores estejam atentos aos sinais iniciais da síndrome pois, ainda que baixas, a amostra apresentou uma certa frequência de EE e DP.

\section{Considerações Finais}

Conclui-se que nas dimensões da síndrome de Burnout, foi possível observar, primeiramente, que a amostra pesquisada não apresenta presença significativa da Síndrome, 
segundo critérios estabelecidos por Schaufeli et al. (2002), uma vez que, médias baixas de exaustão e despersonalização, e altas de realização ou envolvimento no trabalho, não representam indicativos significativos de Burnout. Porém, apresentam estar em um estágio inicial de exaustão emocional e despersonalização, o que faz com que se volte a atenção para esses resultados e se dê a devida importância. No caso deste estudo, verificou-se que a amostra tem incidências de 37,27\% de exaustão, 21,08\% de despersonalização e $88,14 \%$ de realização profissional.

Em conclusão à identificação e à análise das dimensões do Engajamento no Trabalho, a amostra apresentou indicativo de estar engajada. Segundo Schaufeli e Bakker (2003), quanto mais alto o escore identificado em vigor, dedicação e absorção, maior será o Engajamento no Trabalho. Na amostra foram encontradas incidências de 80,14\% de vigor, $78,45 \%$ de dedicação e 78,32\% de absorção. Mesmo que a amostra de trabalhadores do comércio, em sua maioria, esteja engajada com seu trabalho, e não apresente nível significativo de Burnout.

Quanto às limitações da pesquisa, foram a escassez de estudos e conceitos sobre engajamento e estudos específicos em profissionais de cargos que exigem baixa escolaridade e menores responsabilidades. Notou-se que, apesar de esses profissionais não sofrerem pressão relativa a ter grandes responsabilidades dentro da empresa, eles sofrem com a pressão dos empregadores em relação ao alcance de metas e com o estresse da competição entre colegas no trabalho. Apesar de também ser utilizado o método quantitativo, a generalização dos achados não pode ser estendida aos demais profissionais do Estado ou mesmo do Brasil, em função das diferenças e, também, da estrutura e cultura das organizações. Como sugestão de estudos futuros, indica-se a replicação desse estudo em outros contextos e segmentos.

Os resultados obtidos neste estudo apoiam fortemente a prática da gestão de pessoas nas organizações que, por sua vez, precisa também investir nos seus colaboradores criando um clima de relacionamento de amizade, otimismo e confiança dentro do ambiente de trabalho ao verificar que a Síndrome de Burnout e o Engajamento no Trabalho exercem influência sobre o bem-estar no trabalho. Este trabalho teve como objetivo primordial contribuir à área de pesquisa do campo do comportamento organizacional, ampliando os conhecimentos sobre o fenômeno que vem se sobressaindo a gestão de pessoas.

\section{Referências}


BAKKER, A. B.; DEMEROUTI, E.; SCHAUFELLI, W. B.; XANTHOPOULOU, D. Reciprocal relationships between job resources, personal resources, and work engagement. 2008. 10 f. Artigo. Journal of Vocational Behavior. Elsevier: Amsterdã, 2008.

DEJOURS C. A loucura do trabalho: estudo de psicopatologia do trabalho. 5. ed. São Paulo: Cortez, 1992.

DEJOURS, C. Subjetividade, trabalho e ação. Revista Produção, v. 14, n. 3, 27-34, 2004.

HALABI, E. N. Editora Alto Astral. Síndrome de Burnout: algumas profissões que estão no grupo de risco. 2017. Disponível em: https://www.altoastral.com.br/sindrome-burnoutprofissoes-risco/. Acesso em: 9 jul. 2019.

KAHN, W. A. Psychological conditions of personal engagement and disengagement at work. Academy of Management Journal, v. 33, n. 4, 692-724, 1990.

MASLACH, C.; JACKSON, S. E. Maslach Burnout Inventory. 2. ed. Palo Alto, CA: Consulting Psychologist Press, 1986.

MASLACH, C.; SCHAUFELI, W. B. Historical and conceptual development of burnout. In W. B. Schaufeli, C. Maslach, \& T. Marek (Eds.), Series in applied psychology: Social issues and questions. Professional burnout: Recent developments in theory and research. Philadelphia, PA, US: Taylor \& Francis, 1993. p. 1-16.

MASLACH, C. Burnout: A Multidimensional Perspective. In: Schaufeli, W.B.; Maslach, C. \& Marek, T. (Eds.), Professional burnout: recent developments in theory and research. New York: Taylor \& Francis, 1993. p. 19-32.

MASLACH, C. Maslach Burnout Inventory, Manual. University of California, Consulting Psychologists: Palo Alto, 1999.

MASLACH, C.; LEITER, M. P. Trabalho: fonte de prazer ou desgaste. Papirus, Campinas, 1997.

MASLACH, C.; SCHAUFELI, W. B.; LEITER, M. P. Job burnout. Annual Review Psychology, v. 52, n. 1, 397-422, 2001.

SCHAUFELI, W. B.; BAKKER, A. B. 'Werk en welbevinden: Naar een positieve benadering in de Arbeids-en Gezondheidspsychologie' [Work and well-being: Towards a positive Occupational Health Psychology] Gedrag \& Organisatie, pp. 229-253, 2001.

SCHAUFELI, W. B.; SALANOVA, M.; GONZALEZ-ROMÁ, V.; BAKKER, A. B. The measurement of engagement and burnout: a two sample confirmatory factor analytic approach. Journal of Happiness Studies, v.3, p.71-92, 2002.

SCHAUFELI, W.; BAKKER, A.; UWES-Utrecht Work Engagement Scale Preliminary Manual Occupational. Health Psychology Unit Utrecht University, 2003. Adaptado e 
traduzido por: ANGST, R., BENEVIDES-PEREIRA, A. M. T., PORTO-MARTINS, P. C. Escala de Engagement do Trabalho de Utrecht, 2009.

SELIGMAN, M. Positive psychology, positive prevention, and positive therapy. In C. R. Snyder, \& S. J. Lopez (Eds.), Handbook of positive psychology. New York: Oxford University Press, 2002. p. 3-9.

TRIGO, T. R.; TENG, C. T.; HALLAK, J. E. C. Síndrome de burnout ou estafa profissional e os transtornos psiquiátricos. Rev. Psiq. Clín., v. 34, n. 5, p. 223-233, 2007. p. 223-233. 